\title{
Effect of Familial Functioning on Academic Stress: A Study of Differently Abled Adolescents
}

\author{
Amit K. Sharma
}

\begin{abstract}
Almost certainly about it, puberty is a period of high academic stress for teenagers and parents alike especially in case of physically challenged adolescents. Stress is the typical aftereffect of any fast change, and quick change is the thing that immaturity is about. As a parent, individuals watch that his kid adapts to the academic stress and, he trust, become more grounded from the experience. The current examination worried about academic stress among physically challenged adolescents. An example of 30 physically challenged adolescents (age 14 to 19 years) and 30 guardians (age 40 to 50 years) was taken by utilizing basic arbitrary inspecting strategy to gauge the academic stress and discover the impact of parent's psychological wellbeing, family pathology and locus of control on academic stress of these adolescents. The consequences of present examination show that there is huge contrast between Parent's Mental Health and Adolescent's Academic Stress. So it very well may be said that parent's emotional well-being and Family Pathology advances the degree of academic stress in youths. Be that as it may, there is no critical distinction between parent's locus of control and Adolescent's academic stress.
\end{abstract}

Keywords: Academic Stress, Family Pathology, Locus of control, Mental Health.

\section{INTRODUCTION}

Everyone doesn't have to tell that academic tensions build during secondary school, especially the most recent two years. Furthermore, albeit numerous guardians perceive that academic battles - to abstain from bombing a significant course, for instance - can be very upsetting, it might be the most academically capable students who feel the best weight, as they find themselves competing for scarce, highnotoriety school spots. Companion bunch stress will in general be most elevated during the center school years, yet adolescents who don't discover in any event an insignificant level of acknowledgment around then in their lives are probably going to endure enduring outcomes: separation, low confidence, and stress. The cost of admission to cool friend society for some, young people is inclusion with cigarettes, liquor, and medications. For certain adolescents, substance Use gives transitory alleviation from stress.

In any case, over the long haul the physical and mental high points and low points wind up expanding, not diminishing, the degree of stress they feel. Stress is an inclination that is made when we respond to specific occasions. It's the body's method for adapting to the situation and getting ready to meet a predicament with center, quality, stamina, and increased readiness.

Revised Manuscript Received on May 15, 2020.

* Correspondence Author

Dr. Amit K. Sharma*, Assistant Professor Department of Psychology Mewar University Chittorgarh (Rajasthan)

(C) The Authors. Published by Blue Eyes Intelligence Engineering and Sciences Publication (BEIESP). This is an open access article under the CC BY-NC-ND license (http://creativecommons.org/licenses/by-nc-nd/4.0/)
The occasions that incite stress are called stressors, and they spread an entire scope of circumstances everything from inside and out physical peril to making a class introduction or taking a semester of your hardest subject.

The human body reacts to stressors by enacting the sensory system and explicit hormones. The hypothalamus signals the adrenal glands to produce more of the hormones adrenaline and cortisol and release them into the bloodstream. These hormones accelerate pulse, breathing rate, circulatory strain, and digestion. Veins open more extensive to let more blood stream to huge muscle gatherings, putting our muscles on alert. Students enlarge to improve vision. The liver discharges a portion of its put away glucose to build the body's vitality. Also, sweat is delivered to cool the body.

These physical changes set up an individual to respond rapidly and adequately to deal with the weight existing apart from everything else. This regular response is known as the stress reaction. Working appropriately, the body's stress reaction improves an individual's capacity to perform well under tension. Be that as it may, the stress reaction can likewise cause issues when it blows up or neglects to kill and reset itself appropriately.

Stress is the physiological and passionate response to mental occasions. Any occasion setting off the in the past life-sparing, antiquated "battle or flight" reaction is a stressor. The limitations of present day society plainly preclude escaping from or genuinely opposing most upsetting occasions (e.g., coming up short on a homeroom when an unexpected test is given, contending with the educator not to give a test). Unrelieved, the combined, physical strain created by mental stress can hurt the body. Stress is regularly experienced as a reliable, misrepresented, and overpowering need to keep moving, frequently combined with disappointment.

Immature anxieties originate from inside - that is, they can have a natural reason - just as from the different social circles wherein young people work: the family, school, peer gathering, and the general public on the loose. When all is said in done, the physical changes of puberty happen most quickly from age 12 to 14 for young ladies and somewhere in the range of 13 and 15 for young men. Notwithstanding, or maybe in view of, their bodies' fast changes, adolescents will in general be incredibly reluctant and commonly expect that everybody is continually gazing at them. Each pimple, each undesirable bend or absence of bends, can be a wellspring of hopelessness and stress, especially for the individuals who don't accommodate our way of life's thin perfect of excellence. Simultaneously, young people's busier-than any time in recent memory plans - rotating around school, work, and mingling - contend with an expansion in their natural requirement for rest.

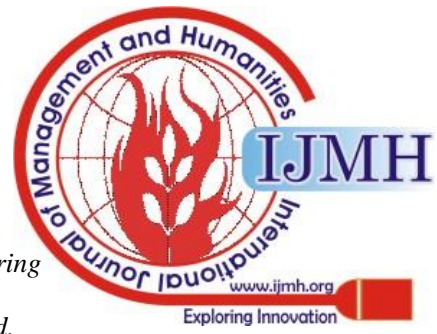


The outcome is that lack of sleep is another, frequently quiet, wellspring of stress. Indeed, even the balanced youths face a significant wellspring of worry in their associations with their folks. That is on the grounds that each immature must work through

the deep rooted battle between the need to have a place and with be dealt with, and the requirement for autonomy and opportunity. The current examination worried about academic stress among physically challenged adolescents according to their familial working. Familial working shows the Mental Health, Family Pathology and Locus of control of the guardians. Study measure the academic stress of the chose youths and discover the impact of parent's emotional well-being, family pathology and locus of control on the equivalent.

\section{OBJECTIVES OF THE STUDY}

1. To find out the effect of mental health of parents on academic stress of physically disabled children.

2. To find out the effect of family pathology of parents on academic stress of physically disabled children.

3. To find out the effect of locus of control of parents on academic stress physically disabled children.

\section{REVIEW OF LITERATURE}

In the zone of Education framework, freedom to incapacitated kids and academic stress Nail Gordon (1992) inspected the challenges in giving even relative autonomy to impaired youngsters are audited. What's more, that training must be practically founded on the youngster's capacity and likely possibilities on leaving school to adapt academic stress.

Silver, Larry B. M.D. 1989 portrayed that incapacities not just meddle with academic errands; they meddle additionally with all phases of psychosocial advancement just as with friend and family communications. It isn't extraordinary, consequently, for youngsters and youths with learning incapacities to have mental, friend, and family issues.

Vasudevan, and Sridhar, V. (1989) characterized handicap as a conduct reaction to proceeded "weakness" the limits the presentation of typical capacity. Handicap assurance includes various elements that may impact the capacity to take part in profitable action, including age, sex, instructive, financial, and social condition the connection among agony and incapacity includes on the physiological, physical and professional capacity of the person.

Shmuel Shulman, Steven Carlton-Ford, Rivka Levian and Sara Hed (1994) found that moms of learning incapacitated adolescents tend more to look for and acknowledge help. Learning impaired young people's adapting is unmistakably identified with adapting or all the more explicitly to challenges in adapting of their folks.

\section{RESEARCH METHODOLOGY}

SAMPLING: A sample of 30 physically challenged adolescents (age 14 to 19 years) and 30 parents (age 40 to 50 years) was taken by using simple random sampling technique to measure the academic stress And find out the effect of parents' mental health, family pathology and locus of control on academic stress of these adolescents.

Table 1: Sample Distribution

\begin{tabular}{|c|c|c|c|}
\hline Sr. No. & Participants & $\mathrm{N}$ & $\sum$ \\
\hline 1. & $\begin{array}{c}\text { Parents } \\
\text { (Age Range 40-50 Years) }\end{array}$ & 30 & \multirow{2}{*}{60} \\
\hline 2. & $\begin{array}{c}\text { Students } \\
\text { (Age Range 40-50 Years) }\end{array}$ & 30 & \\
\hline
\end{tabular}

\section{NULL HYPOTHESES:}

$\mathrm{H}_{0} 1$ : There is no significant difference between parents's Mental Health on academic stress among physically disabled children.

$\mathrm{H}_{0}$ 2: There is no significant difference between parents's Family Pathology on academic stress among physically disabled children.

$\mathrm{H}_{0} 3$ : There is no significant difference between parents's Locus of control on academic stress among physically disabled children.

VARIABLES OF THE STUDY:

Independent: Mental health, Family pathology \& Locus of control of the adolescents are taken as independent variables.

Dependent: As a dependent measure this study concerned academic stress of physically challenged adolescents.

TOOLS:-

1. Mithila Mental Health Status Inventory: Dr.G.P.Thakur \& Dr. Anand Kumar (1996).
2. Family Pathology Scale: Vimla Veeraraghavan \& Archna Dogra (2000).

3. Rotter's Locus of Control Scale: Dr. Anand Kumar \& Dr. S. N. Srivastava (1995).

4. Student Stress Scale (S.S. Scale): Dr. Taresh Bhatia \& Arunima Pathak (2005).

DATA COLLECTION:

The Data Collection was done using random sampling procedure. The general instructions were given to participants to complete the Scale. Filled questionnaires were collected from participants for statistical analysis of data. The Statistical Analysis was conducted. The Mean and t-test was calculated.

Published By:

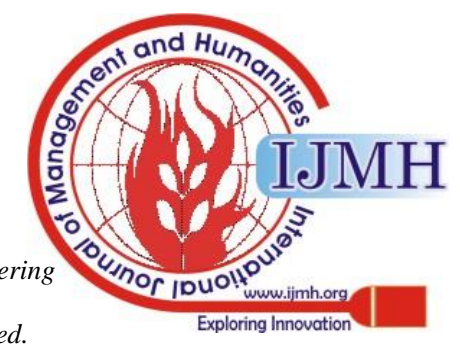




\section{DATA ANALYSIS AND INTERPRETATION}

Table 2: Mean, S.D. \& T-Value

(Academic Stress $\times$ Parent's Mental Health)

\begin{tabular}{|c|c|c|c|c|c|c|}
\hline S.No. & & $\mathrm{N}$ & Mean & S.D. & t-Values & Sign. \\
\hline 1 & $\begin{array}{c}\text { Parent's Mental } \\
\text { Health }\end{array}$ & 30 & 15.58 & 6.51 & 8.05 & 0.01 \\
\hline 2 & $\begin{array}{c}\text { Adolescent's } \\
\text { Academic Stress }\end{array}$ & 30 & 11.4 & 1.46 & \\
\hline
\end{tabular}

The results in Table 2 indicate that Parent's Mental Health has higher mean score in comparison to Adolescent's Academic Stress. Calculated t- value is 8.05, which is significant at 0.01 level. Therefore, it can be said that there is significant difference between Parent's Mental Health and Adolescent's Academic Stress.

Table 3: Mean, S.D. \& T-Value

(Academic Stress $\times$ Parent's Family Pathology)

\begin{tabular}{|c|c|c|c|c|c|c|}
\hline S.No. & & $\mathrm{N}$ & Mean & S.D. & t-Values & Sign. \\
\hline 1 & $\begin{array}{c}\text { Parent's Family } \\
\text { Pathology }\end{array}$ & 30 & 16.52 & 6.42 & 10.05 & 0.01 \\
\hline 2 & $\begin{array}{c}\text { Adolescent's } \\
\text { Academic Stress }\end{array}$ & 30 & 11.4 & 1.46 & \\
\hline
\end{tabular}

The results in Table 2 indicate that Parent's Family Pathology has higher mean score in comparison to Adolescent's Academic Stress. Calculated t- value is 10.05 , which is significant at 0.01 level. Therefore, it can be said that there is significant difference between Parent's Family Pathology and Adolescent's Academic Stress.

Table 4: Mean, S.D. \& T-Value (Academic Stress $\times$ Parent's Locus of Control)

\begin{tabular}{|c|c|c|c|c|c|c|}
\hline S. No. & & $\mathrm{N}$ & Mean & S.D. & t-Values & Sign. \\
\hline 1 & $\begin{array}{c}\text { Parent's Locus of } \\
\text { Control }\end{array}$ & 30 & 11.54 & 5.77 & 0.28 & $\begin{array}{c}\text { Not } \\
\text { Significant }\end{array}$ \\
\hline 2 & $\begin{array}{c}\text { Adolescent's } \\
\text { Academic Stress }\end{array}$ & 30 & 11.4 & 1.46 & \\
\hline
\end{tabular}

The results in Table 2 indicate that Parent's Locus of Control has higher mean score in comparison to Adolescent's Academic Stress. Calculated t- value is 0.28 , which is not significant at any level. Therefore, it can be said that there is no significant difference between Parent's Family Pathology and Adolescent's Academic Stress.

\section{VI.CONCLUSION}

It is concluded that there is significant difference between Parent's Mental Health and Adolescent's Academic Stress. So $\mathrm{H}_{0} 1$ is rejected at 0.01 level. Mental health helps to adjusting well in social and familial problems. The results of present study show that parent's mental health promotes the level of academic stress in adolescents.

There is significant difference between Parent's Family Pathology and Adolescent's Academic Stress. So $\mathrm{H}_{0} 2$ is rejected at 0.01 level. Parent's pathological family pattern indicates the major or minor physical or psychological problems in family of an individual.
The results of present study show that parent's Family Pathology promotes the level of academic stress in adolescents. With internal locus of control, an individual has believed in his self to stand against the critical situations of social life. There is no significant difference between parent's Locus of control on academic stress among physically disabled children. According to results of the present study $\mathrm{H}_{0} 3$ is accepted. So it can be said that there is significant difference between parent's locus of control and Adolescent's academic stress.

\section{REFERENCES}

1. Conner, Michael J. (1995) Locus of Control, Therapeutic Care and Education, 4, 16-26.

2. Findley, M. J. \& Cooper, H. M. (1983) Locus of control and academic achievement: A literature review. Journal of Personality and Social Psychology, 44, 419-427.

Published By:

Blue Eyes Intelligence Engineering

\& Sciences Publication and $\mathrm{Hu}$

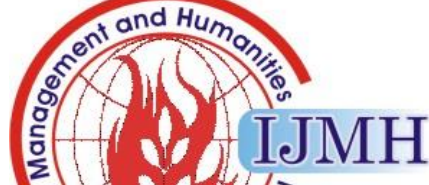

Copyright: All rights reserved. 
Effect of Familial Functioning on Academic Stress: a study of Differently Abled Adolescents

3. Gordon, Nail, D. R. \& Kelley, K. N. (1992) Improving the performance of failing students by overcoming their self-serving attribution biases, Basic and Applied Social Psychology, 8, 151-162. (p.48)

4. Shulman Shmuel, Carlton-Ford Steven, Levian Rivka and Hed Sara, (1994) coping styles of 50 learning disabled and non learning disabled adolescents and their parents, Journal of Social Psychology, vol. 3(4), 177-189.

5. Silver, Larry B. (1989) Psychological and Family Problems Associated with Learning Disabilities: Assessment and Intervention, American Journal of Adolescent. 32, 67-73.

6. Suter C., Meyer P.C. (1994) Social support, social stress and health of slightly disabled elderly persons, German psychological reviews, 42, (3-6) 1-7.

7. Vasudevan, Sridhar, V. (1989) Clinical perspectives on the relationship between pain and disabilities, Neurological, clinic, 7 (2), 429-439. (1) 